\title{
Sensorial saturation: A new approach to babies' pain
}

\section{Carlo Valerio Bellieni*}

Medical Director, Department of Pediatrics, University of Siena, Italy

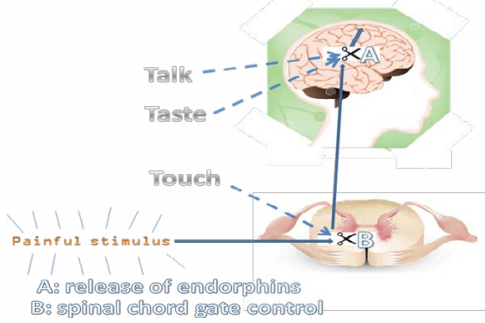

Figure 1. The simultaneous use of touch, voice and taste stimulation, inhibits pain to attain the brain during common painful procedures. This is due to endorphin release in the brain and to neuronal gate-control in the spinal cord. Babies feel pain more than adults, and common strategies, like the isolated use of oral sugar, are not effective enough.

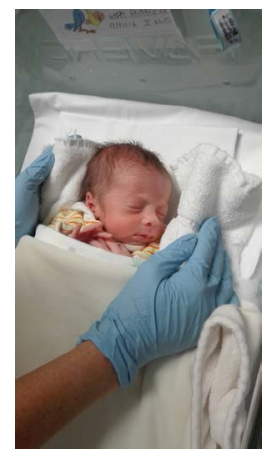

Figure 2. Preparatory stage of the "sensorial saturation" procedure: holding the baby. The baby is contained and the sheet tucked before the procedure.
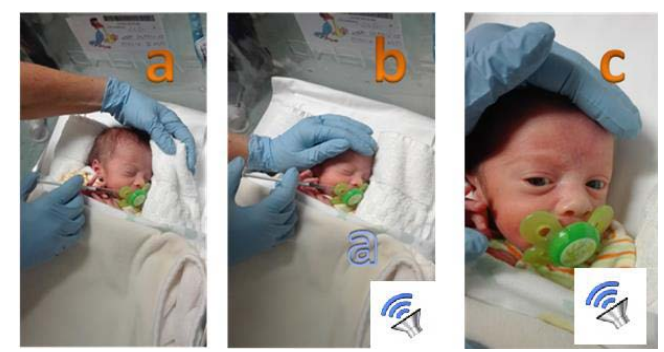

Figure 3.

a) First stage: sweet taste. Oral sugar (0.1-1 ml of 33\% glucose in sterile water) and a pacifier are offered to the baby, provoking the

Copyright: (C2016 Bellieni CV. This is an open-access article distributed under the terms of the Creative Commons Attribution License, which permits unrestricted use, distribution, and reproduction in any medium, provided the original author and source are credited. sucking reflex for 30 seconds before and throughout the procedure

b) Second stage: talk and touch. The baby is massaged and his nurse or his mother talks to him, attracting his attention, while suction is still elicited: this begins 30 seconds before the heel-prick, and continues throughout.

c) Third stage: sight and sucking. When the baby is staring and the sucking becomes regular ( 1 suction/second), the painful procedure (in this case a heel lancing) can be performed.

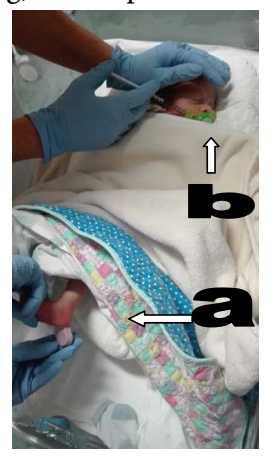

Figure 4. The painful procedure is now painless, the foot can be lanced (a) without pain signals (b), as it emerges from several research papers.

\section{Consent}

All the pictures have been taken and published with the express approval of the baby's parents.

A video clip of the procedure is available at the following URL: https://www.youtube.com/watch?v=Hu6Xdy7LIAQ

Correspondence to: Carlo Valerio Bellieni, Medical Director, Department of Pediatrics, University of Siena, Italy, Tel: 0039-347 357-4566, Fax: 00390577586182,E-mail: cvbellieni@gmail.com

Received: November 07, 2016; Accepted: November 11, 2016; Published: November 14, 2016 